\title{
Swimming pool immersion accidents: an analysis from the Brisbane Drowning Study
}

\author{
John H Pearn, James Nixon
}

This is the 14th paper in a series of Injury Classics. Our goal is to reprint one or two such papers in each issue to introduce newcomers to these old, often quoted, and important contributions. As many are difficult to find, it should help all of us to have a copy to hand. Your suggestions about future articles are welcome. Write to the editor with details of your favourite, most quoted paper.
University of
Oueensland, Australia

This paper first appeared in the Medical fournal of Australia (1977; i: 432-7) and is reproduced with permission.

\section{Abstract}

An analysis of a consecutive series of 66 swimming pool immersion accidents is presented; $74 \%$ of these occurred in inground swimming pools. The estimated accident rate per pool is fives times greater for in-ground pools compared with above-ground pools, where pools are inadequately fenced. Backyard swimming pools account for $74 \%$ of pool accidents. Motel and caravan park pools account for $9 \%$ of childhood immersion accidents, but the survival rate $(17 \%)$ is very low. Fifty per cent of pool accidents occur in the family's own backyard pool, and $13.6 \%$ in a neighbour's pool; in the latter the survival rate is still low at only $33 \%$. In only one of the 66 cases was there an adequate safety fence; in $76 \%$ of cases there was no fence or barrier whatsoever. Tables of swimming pool accidents by age, season, site, and outcome are presented.

Child drowning in swimming pools are common. Immersion accidents involving children are increasing worryingly in some centres. ${ }^{1}$ This increase has been coincident in time with a dramatic increase in the installation rate of home swimming pools. ${ }^{2}$ Drowning accidents involving children under the age of 6 years exceed deaths due to motor vehicle accidents in all Australian states. ${ }^{3-9}$ Because of the serious epidemiological position that drownings and near-drownings now occupy, we have felt that a specific analysis of swimming pool incidents is urgently required. This paper reports the findings from a series of 66 consecutive swimming pool drownings and near-drownings over the five year period 1971 to 1975 inclusive. This report furnishes further data from the Brisbane Drowning Study. ${ }^{1}$

\section{Methods}

Details of case-finding, parental interviews, approachs to family doctors, use of coroner's reports and hospital records have been described previously. ${ }^{1}$ All cases of swimming pool immersion incidents in which consciousness was lost in the water, without selection, have been included.

\section{SWIMMING POOLS}

A swimming pool has been defined as a receptacle containing water, specifically constructed for swimming or water recreation.
This definition has necessitated the exclusion, from our study, of immersion accidents in ornamental pools and ponds (1 case), dams on rural properties (5 cases), and waterholes and sumps containing water (6 cases).

The swimming pool involved was visited in all 38 instances in which the victim survived, and in approximately one third of the 28 fatal cases: details of the type of pool (in-ground versus above-ground), construction, depth of water, presence of safety barriers, type and construction of gates, and the distance from the child's own home were compiled. An estimate of water temperature was obtained from the files of the Commonwealth Bureau of Meterology. It happened that all pools in this study contained chlorinated fresh water, but the degree of water pollution (particularly with green algae) differed from case to case. One pool was involved in two immersion accidents, one fatal.

\section{IMMERSION ACCIDENT}

An account of the accidents was obtained by interviews with parents, neighbours, resuscitators and family doctors, and by reference to coronial and forensic pathology files and hospital records. All relevant details were recorded; these included precipitating factors, day of the week and time of day, clothes worn by the victim (with particular respect to their buoyancy properties), immersion period, details of rescue or extraction, and subsequent resuscitation efforts.

\section{Results}

Details of the 66 swimming pool accident victims, by outcome and type of pool, are shown in table 1 . It can be seen that $74 \%$ of the accidents (49 cases) occurred in in-ground pools. This is particularly significant, as inground pools comprise only $34 \%$ of all backyard pools in the City of Brisbane. ${ }^{2}$ It can be calculated that in-ground pools are more likely to be involved in a child's drowning or neardrowning, by a factor of five. Survival rates for the two pool types (59\% for in-ground, and $53 \%$, for above-ground pools) do not differ significantly once consciousness is lost in the water $(\mu=0.43, \mathrm{p}<0.1)$.

Table 2 shows the different types of pools involved in childhood immersion accidents, by outcome. It can be seen that privately owned backyard pools (74\%) account for most accidents. The data in table 2 can also be used to give some insight into the relative efficacy of 
Table 1 Details of 66 consecutive childhood immersion accidents involving swimming pools by type of pool and by outcome

\begin{tabular}{llcl}
\hline & \multicolumn{3}{l}{ No of accident victims } \\
\cline { 2 - 4 } & $\begin{array}{l}\text { In-ground } \\
\text { pools }\end{array}$ & $\begin{array}{l}\text { Above-ground } \\
\text { pools }\end{array}$ & Total \\
\hline Survivals & 29 & 9 & 38 \\
Facilities & 20 & 8 & 28 \\
Total & 49 & 17 & 66 \\
\hline
\end{tabular}

Table 2 Details of 66 consecutive childhood immersion accidents by site, and by outcome

\begin{tabular}{lrrr}
\hline & \multicolumn{3}{c}{ No of accidents } \\
\cline { 2 - 4 } Site of accident & Survivals & Fatalities & Total \\
\hline Backyard swimming pools: & & & \\
In-ground & 19 & 13 & 32 \\
Above-ground & 9 & 8 & 17 \\
Public swimming baths & 7 & 2 & 9 \\
School swimming pools & 2 & 0 & 2 \\
Other & 1 & 5 & 6 \\
Total & 38 & 28 & 66 \\
\hline
\end{tabular}

^Includes motel and caravan park swimming pools.

Table 3 Geographic location of $65^{*}$ swimming pools involved in immersion accidents by outcome

\begin{tabular}{lllll}
\hline & \multicolumn{3}{l}{ No of accidents } & \\
\cline { 2 - 5 } & $\begin{array}{l}\text { Own backyard } \\
\text { pool }\end{array}$ & $\begin{array}{l}\text { Neighbour's } \\
\text { pool }\end{array}$ & $\begin{array}{l}\text { Friends/ } \\
\text { relatives pool }\end{array}$ & Other \\
\hline Survivals & 21 & 3 & 1 & 13 \\
Fatalities & 12 & 6 & 2 & 8 \\
Total & 33 & 9 & 3 & 21 \\
\hline
\end{tabular}

^One pool was involved in two immersion accidents.

rescue and resuscitation efforts in school pools and public swimming baths; in the latter the survival rate is $82 \%$ even after consciousness is lost in the water. By sharp contrast, although motel and caravan park pools account for only $9 \%$ of all childhood immersion accidents, they are particularly tragic, as only $17 \%$ of victims survive in such surroundings once consciousness is lost.

Table 3 shows the geographical location of the 65 pools involved. It can be seen that immersion accidents most commonly occur $(50 \%)$ in the child's own backyard pool and $13.6 \%$ occur in a neighbour's backyard pool. The latter statistic is of particular significance, as the survival rate in such situations is only $33 \%$. This high mortality is partly due to the fact that it takes longer to find a missing toddler who has wandered from home and who is drowning in a neighbour's pool.

Figure 1 shows the age distribution of all swimming pool immersion victims in the study. The skewed distribution is compatible with the interpretation that there are two overlapping subpopulations, probably differing in aetiological factors. This impression is supported by anecdotal data from the parents of older children, who note that the drowning scenario sometimes is of a child who is in unrecognized difficulties in a crowd of swimmers. This impression - that childhood pool accidents fall into at least two separate categories-is given support by figure 2 , which shows the age distribution of children who died.

Table 4 shows data obtained from a study of safety barriers used to protect the pools in

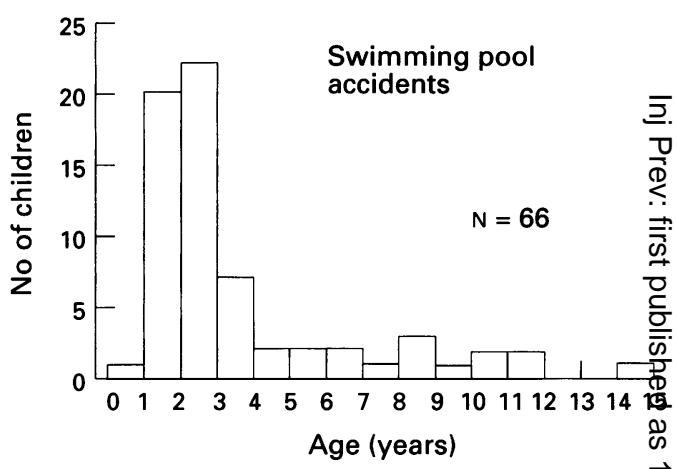

Figure 1 Age frequency distribution histogram for 66 children who suffered swimming pool immersion accidents (Brisbane Drowning Study, 1971 to 1975 inclusive).

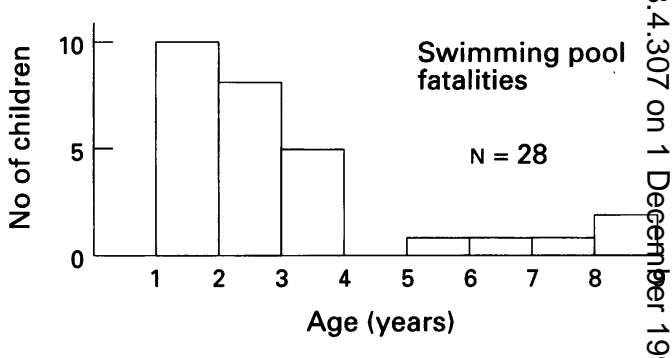

Figure 2 Age frequency distribution histogram for $2 \&$ swimming pool fatalities (Brisbane Drowning Study).

Table 4 Presence or absence of safety barriers surroundin swimming pools, by outcome of the immersion accident, in 58 accidents involving backyard, motel, and caravan pari pools*

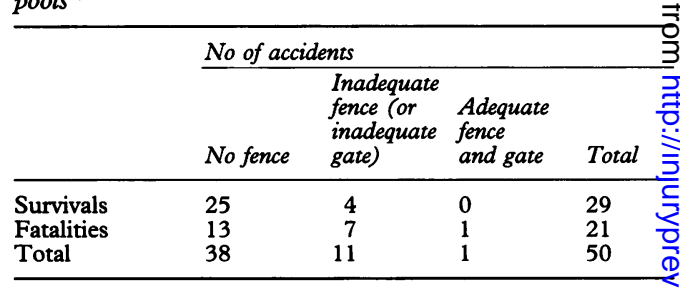

^Excludes public and school swimming pools.

which an immersion accident occurred. It cak be seen that in $76 \%$ of cases there were nQ safety fences or barriers whatsoever. In one case only could there be said to have been an adequate fence and gate (in this instance drowning was due to the misuse of a retract able ladder leading into the enclosed poots area). In $22 \%$ of immersion accidents some attempt had been made to erect a fence before the accident; in these cases either the fence of the gate, or both, was technically inadequate as a practical safety barrier.

The data in table 4 also indicate that as inadequate fence (as opposed to no fence) mayo have inherent danges of its own; such may lu $\bar{\Phi}$ the pool owner into a false sense of security. I can be seen that the survival rate for unfence $\Phi$ pools is $65.8 \%$ compared with a rate of $36 \%$ foo those pools with a fence, but a technically inadequate one $(0.05>p>0.01)$. As the prino cipal factor determining the survival rate is the immersion period before extraction from the water, this suggests that children who fall into an inadequately fenced pool are at particular risk once they enter the water. Parents tend to 


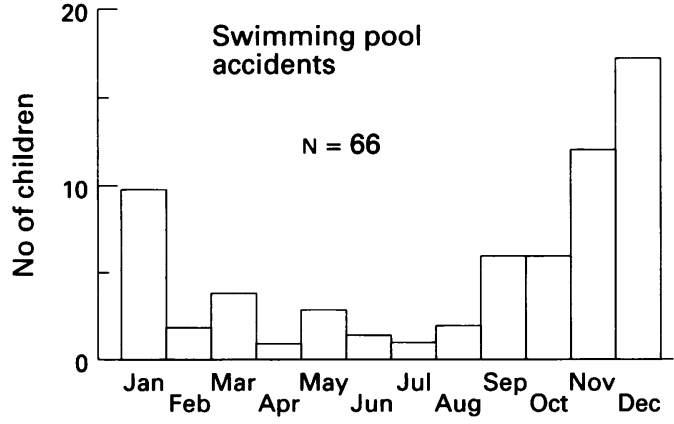

Figure 3 Frequency distribution histogram for the month of occurrence of 66 consecutive swimming pool immersion accidents (Brisbane Drowning Study).

Table 5 Swimming pool immersion accidents by season of occurrence

\begin{tabular}{lrc}
\hline Season & No of accidents \\
\hline Summer (Dec to Feb) & 29 & $(43.9 \%)$ \\
Autumn (Mar to May) & 8 & $(12.1 \%)$ \\
Winter (Jun to Aug) & 5 & $(7.6 \%)$ \\
Spring (Sep to Nov) & $24(36.4 \%)$ \\
Total & $66(100.0 \%)$ \\
\hline
\end{tabular}

relax vigilance of a young child if they imagine (wrongly) that a water harzard is adequately fenced.

Figure 3 shows the swimming pool accident rate by month of occurrence. The immersion accident rate is very high in spring and summer, but the autumn and winter months nevertheless still account for some $20 \%$ of accidents (table 5). These figures reinforce the fact that, on a wintry day, however uninviting a cold pool may look in adult eyes, to a toddler an exposed water hazard may be fatally seductive. Although January and February are Brisbane's two hottest months, the immersion accident rate is less than half $(41.4 \%)$ that observed in November and December. We believe that this may indicate that the publicity regarding drowning accidents (which always starts to increase in spring and early summer) may make parents more aware of the threat as the 'pool season' wears on.

\section{Discussion}

It is known that the drowning and neardrowning rate is running parallel with the rate of pool installation, and that pools are not becoming intrinsically more dangerous. ${ }^{2}$ Whilst this is in some respects heartening, it means that, unless protective measures are adopted, the drowning rate will continue to climb as pools become even more popular. Studies from other centres ${ }^{10}$ suggest that adequate safety legislation may prevent an increase in pool deaths, even in spite of a rapid increase in backyard pool installation.

It is commonly said, with some vehemence, that children will still drown even although adequate fences are built. We can find no supporting evidence whatsoever for this view. We have yet to encounter a fatal childhood swimming pool accident in which an effective fence (with a self closing self locking gate) has been present. Victorian data ${ }^{11}$ have shown that, in a minimum of $70 \%$ of swimming pool drownings of children under 10 years of age, there was no fence or safety barrier whatsoever. A large Swedish study of drowning records ${ }^{12}$ has also shown that, in over 300 fatal childhood water accidents, an adequate safety barrier was not present in any instance. The evidence is so strong that we believe it is indefensible for fencing legislation not to be introduced.

The fact that $50 \%$ of those children who drown, or nearly drown, do so in pools not in their own backyard is further evidence for the need for safety legislation. The $13 \%$ of young children who drown in a neighbour's pool compares consistently with the Victorian proportion of $15 \%^{11}$ who drown under similar circumstances.

We further advocate that home swimming pools should be registrable only if the resident owner has a current first aid certificate, since there is good evidence from the Brisbane Drowning Study that this will lift the survival rate in the 'potentially fatal' group.

Serious immersion accidents in public swimming baths form a surprisingly high component (13.6\%). Similar high figures are known from the United Kingdom. ${ }^{13}$ In the United States ${ }^{14}$ swimming pool drownings far outnumber other causes of drowning in the home (bathtubs, wells, cisterns, and so on).

Swimming pools, and the ability to buy them, are becoming more widespread. It will be an epidemiological tragedy of major proportions if this cumulating threat is not recognized, and if this rise in our standard of living continues to be needlessly purchased in children's lives.

We thank Dr John Tonge and Dr Ian Wilkey, of the Laboratory of Pathology and Microbiology, Brisbane, for help with case of Pathology and Microbiology, Brisbane, for help with case finding; Dr Liew Edwards and Dr Patrick, Department of Health, Queensland, for the provision of an Order in Council to enable this work to be undertaken; the Department of Health,
Brisbane City Council, for information; and the Medical Brisbane City Council, for information; and the Medical
Superintendents of the Royal Children's Hospital and the Superintendents of the Royal Children's Hospital and the
Mater Misericordiae Children's Hospital, Brisbane, for permission to use hospital records.

1 Pearn JH, Nixon J, Wilkey J. Freshwater drowning and neardrowning accidents involving children. A five year tota population study. Med f Aust 1976; ii: 942.

2 Pearn JH, Nixon J. A demographic and interpretative study of the potential drowning hazard of swimming pools to children. 1976 (submitted for publication).

3 Australian Bureau of Statistics (Old Office). Causes of Death 1973. Brisbane Australia, table 1: 40 and 45.

4 Australian Bureau of Statistics (West Australian Office) Statistics of Western Australia Demography, 1973, Perth: Australia, table 37: 51 and 53.

5 Australian Bureau of Statistics (Adelaide). Statistical register of South Australia. 1973-1974. Part II. Demography. of South Australia. 1973-1974.

6 Australian Bureau of Statistics (NSW Office). Causes of death, 1973. Sydney: Australia, table 6: 58 and 60.

7 Australian Bureau of Statistics (Tasmania). Causes of death 1974. Hobart: Australia, table 1: 16 and 19.

8 Australian Bureau of Statistics (Victoria) Causes of death, 1973. Melbourne: Australia, table 1: 38.

9 Australian Bureau of Statistics (Northern Territory). Cause of death. Tabulation for Northern Territory, 1973 year. Table ACDD4.

10 Pearn JH, Thompson J. Drowning and near-drowning in the Australian Capital Territory-a five year total population study of immersion accidents. Med $\mathscr{f}$ Aust 1977; i: 30.

11 Australian Bureau of Statistics (Victoria). Accidental drowning in private swimming pools, 1976. Report on Victorian ing in private swimming pools, 1976. Report on Victorian
swimming pool deaths, $1968-1975$. Melbourne, Australia.

12 Thomson J, Fredin H, Gerdman P, Wiklund R. Accidental drowning among children in Sweden 1958-1967. Acta drowning among children in
Sociomed Scand 1970; 2: 149.

13 Alison M. Death in the swimming bath. Nursing Times January, 1971; 56 .

14 National Safety Council (USA). Accident facts. Chicago, Illinois, 1971; 81. 